South African Journal of Geomatics, Vol. 6. No. 1, April 2017

\title{
ASSESSING THE ACCURACY OF REMOTE SENSING TECHNIQUES IN VEGETATION FRACTIONS ESTIMATION
}

\author{
Okuku Josephat Oloo \\ Moi University, P.O Box 3900-30100, Eldoret, Kenya \\ Email: josokuku@yahoo.com
}

DOI: http://dx.doi.org/10.4314/sajg.v6i1.7

\begin{abstract}
This study aimed at exploring different remote sensing (RS) techniques for quantitatively measuring vegetation and bare soil fractions in dune ecosystems along the Kenyan coast. The accurate measurements of field samples are required by Kenya Wildlife for environmental monitoring. The current methodology for measuring fractions (ecological surveys) is biased, expert dependent and subjective, and for this reason, remote sensing techniques have been explored to find a better cost- effective alternative.

Three methods were carried out to estimate different vegetation coverages in field samples and to analyze their performance: classification of photography's taken by hand-held camera, unmixing of aerial photographs, unmixing of Crop scan and Field spec spectral measurements. For these purposes 32 plots of 1x1square meters distributed in 4 transects were selected and measured in the dune ecosystem.

According to the field spectral measurements, different targets (lichens, vascular plants, mosses, and bare soil) showed a large spectral variation and overlapping between their spectral signatures. Therefore, classification methods and unmixing techniques led to poor results since they are based upon the spectral signature of the targets.

The hand held camera method proved more accurate than Field Spec, Aerial photograph and Crop Scan. Therefore, from the remote sensing methods, this is the best method when considering accuracy. The performance of this method could be improved by adding an extra band (Infrared for instance). This extra band would allow operators to identify and classify better different kind of vegetation in the image.
\end{abstract}

Key words: Unmixing, Remote sensing techniques, spectral measurements

\section{Introduction}

The Kenyan coast has a great ecological and economic value. It supports most productive and diverse ecosystems such as coral reefs, mangrove, sand dune and sea grass. These ecosystems are important in shoreline stabilization, reduction of coastal erosion, sediment and nutrient retention, storm protection, flood and flow control, and water quality (Dahdouh-Guebas et al. 2005, Giri et al. 2007, Alongi 2008). Besides, they offer economic benefit through various forest products (Zhang et al. 2006, Gilman et al. 2008and Walters et al. 2008). Its intrinsic beauty and diversity of natural resources has attracted investors for various economic development activities such as 
tourism and recreation, coastal development and urbanization, mining for economic minerals, and quarrying for construction materials, shipping, and fishing are carried out actively throughout the area (Frihy, 2001). The coastal ecosystems is deteriorating in quality and value because of climate change that has affected coastal ecosystems and developments, a situation that worries most scientists and policy makers today (FAO, 2007,Til and Lange,2004 and Frihy, 2001). The Kenyan coastal zone dune ecosystem is a good example of how water supply for human consumption and biodiversity support has been affected (FAO, 2007 and Fromard et al., 2004). The evapotranspiration (ET) can be calculated from climatological records of sunshine, temperature, humidity, and wind speed (UNEP, 2006). However, information about the vegetation cover is also needed to accurately calculate the ET. This makes the vegetation coverage an important input in calculating water availability. Currently this vegetation coverage is obtained visually by ecological surveys. Nevertheless, this method can introduce large biases and is prone to non-systematic errors (Reyneirs et al., 2006). This paper aimed at exploring different remote sensing (RS) techniques for quantitatively measuring vegetation and bare soil fractions in dune ecosystems along the Kenyan coast. Remote sensing is an efficient tool that has been adopted increasingly for the detection, description and monitoring of the Earth's natural resources (Chauhan and Dwivedi 2008). It provides timely and cost-effective data over inaccessible areas (Mumby et al. 1999), complementing field surveys, which are of higher information content but are more difficult to carry out, especially large leave surface area coverage and dense undergrowth of the dune ecosystems (Giri et al. 2007). The current methodology for measuring fractions (ecological surveys) is biased, expert dependent and subjective (Satyanarayana 2007). Many authors have used different approaches like aerial and (optical) satellite images to study the dune ecosystem ecosystems (Dahdouh-Guebas et al. 2000, Lucas et al. 2002, Fromard et al. 2004), while none have compared accuracy of remote sensing techniques (Simard et al. 2008,Bartholy and Pongracz,2005 and Reyneir et al, 2006). It's against this background that this paper explores alternative methods of the estimation of vegetation coverage using multispectral and hyperspetral remote sensing devices; crop scan (2002), field spec (2010) respectively and photography.

\section{Methods}

In order to achieve the objective of this work, estimation of the different vegetation fractions using remote sensing (RS) methodologies was done as stated in the stages described below;

\subsection{Estimation of fractions using remote sensing}

\section{Measurement setup}

The study area corresponds to the dune ecosystem along the Kenyan coast. In this area four dunes were selected for field measurements (Figure1). In the field, a N-S transect for every dune was made which represents one survey transect (Figures 2- 5). This orientation was defined because it covers better the variation on vegetation type and vegetation coverage along the dune. It was observed that the south face showed more amounts of mosses while the north face showed more grasses and mosses coverage. 
South African Journal of Geomatics, Vol. 6. No. 1, April 2017

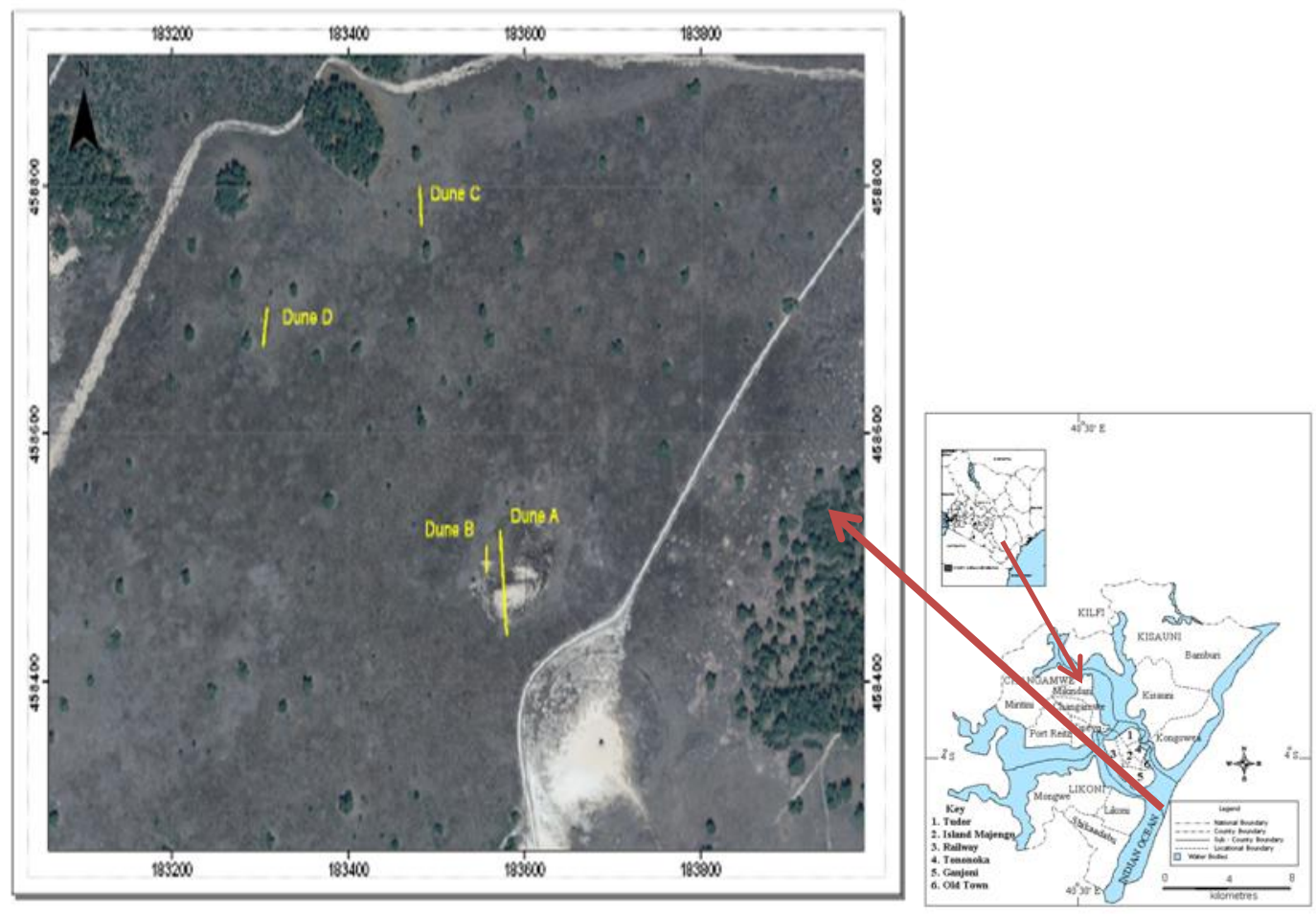

Figure 1: Experimental setup for field measurements

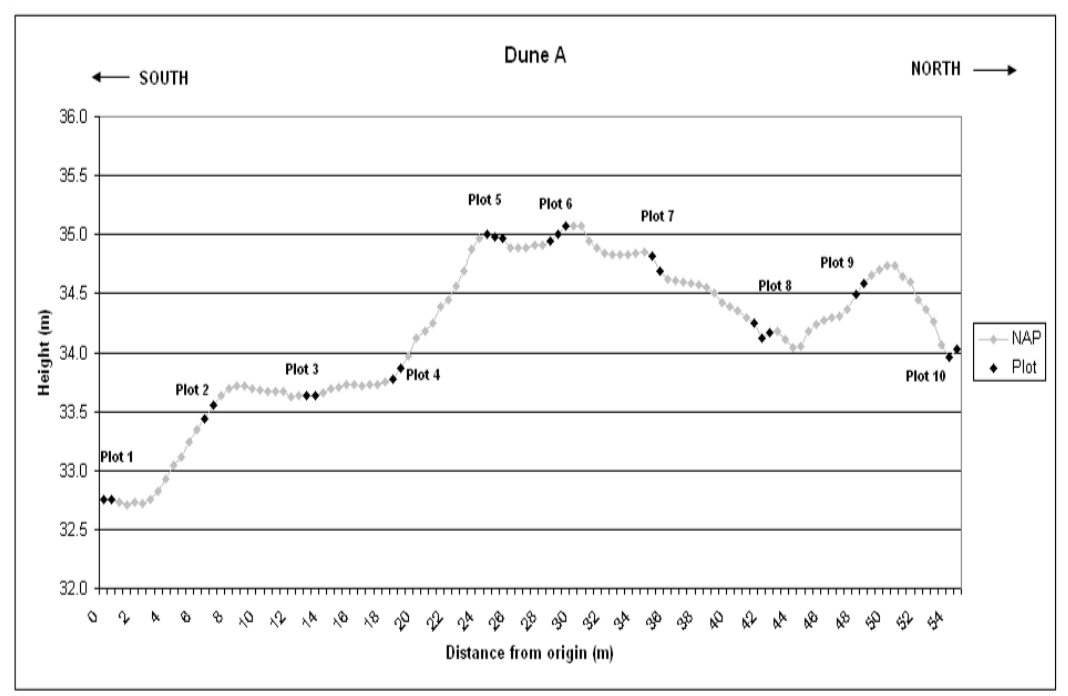

Figure 2: Experimental dune A 
South African Journal of Geomatics, Vol. 6. No. 1, April 2017

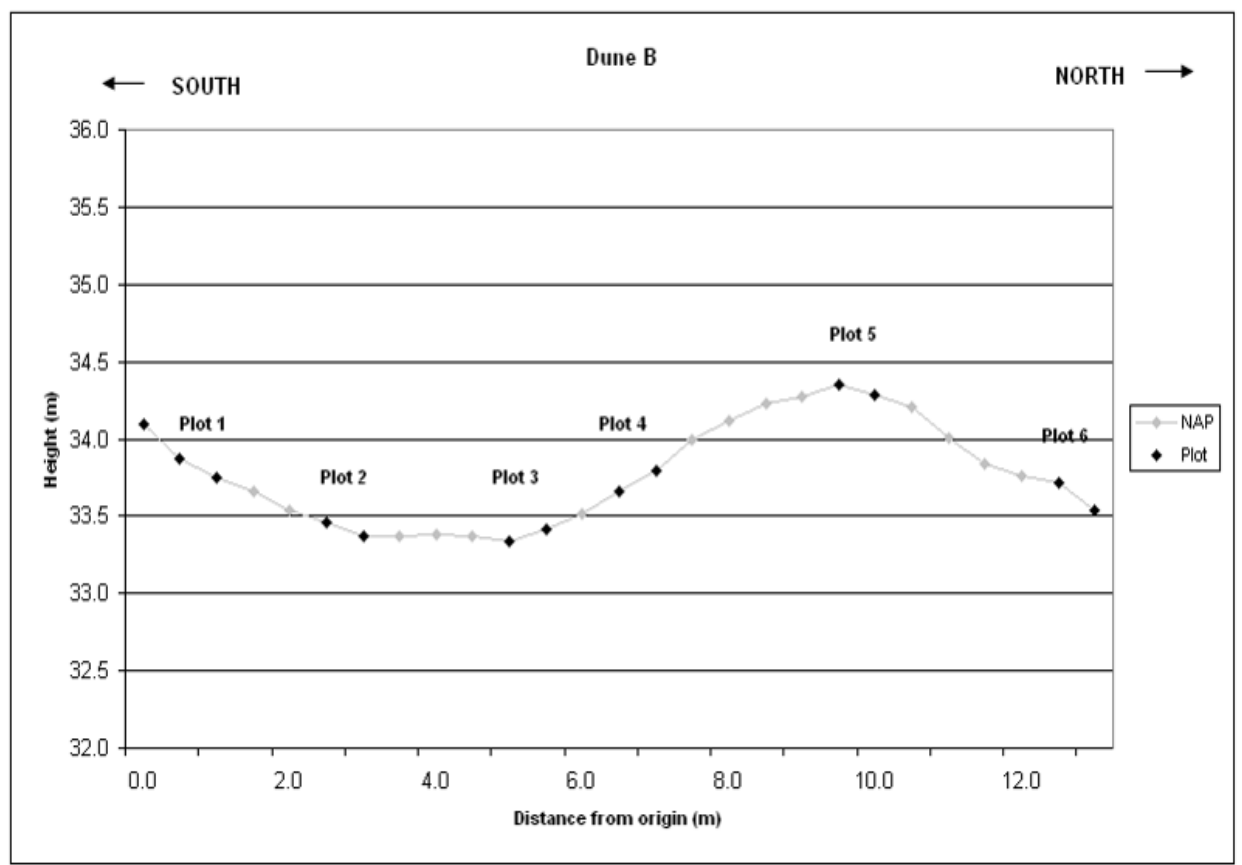

Figure 3: Experimental setup Dune B

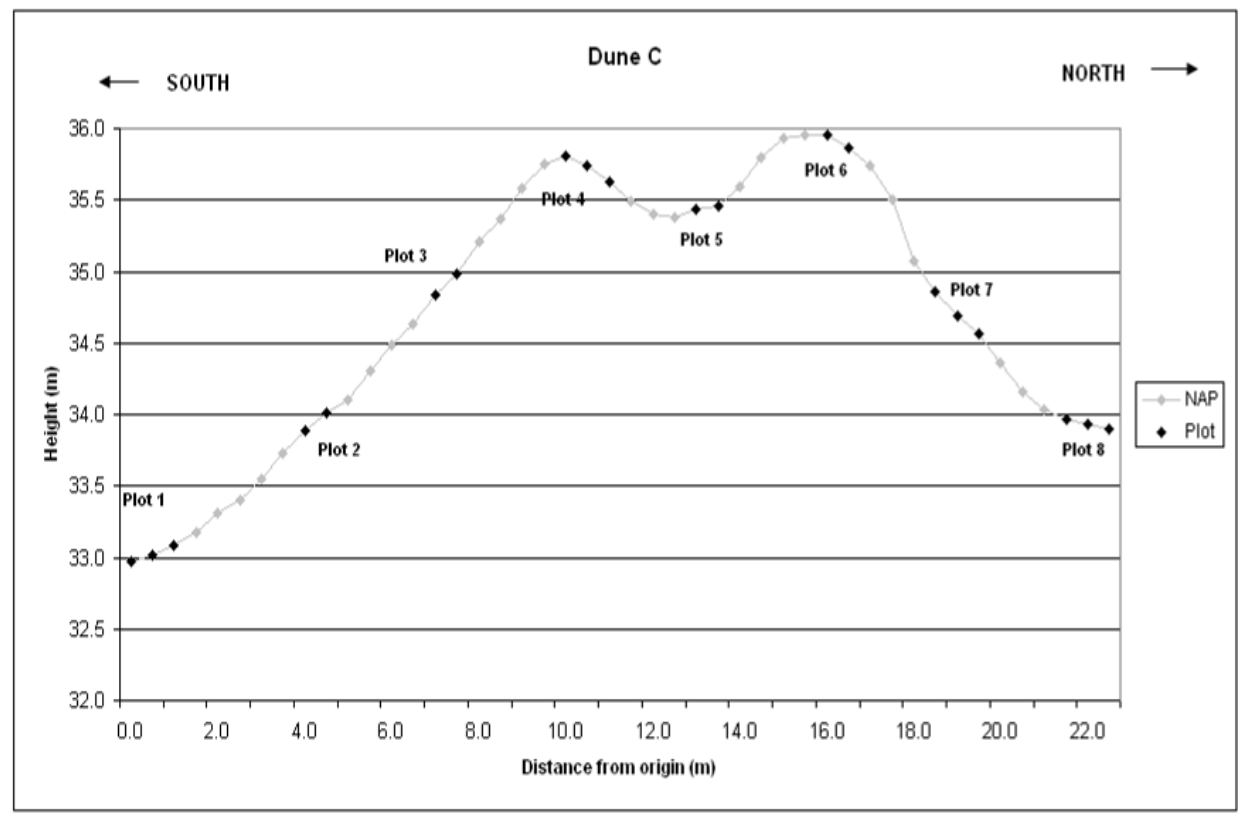

Figure 4: Experimental setup Dune C 


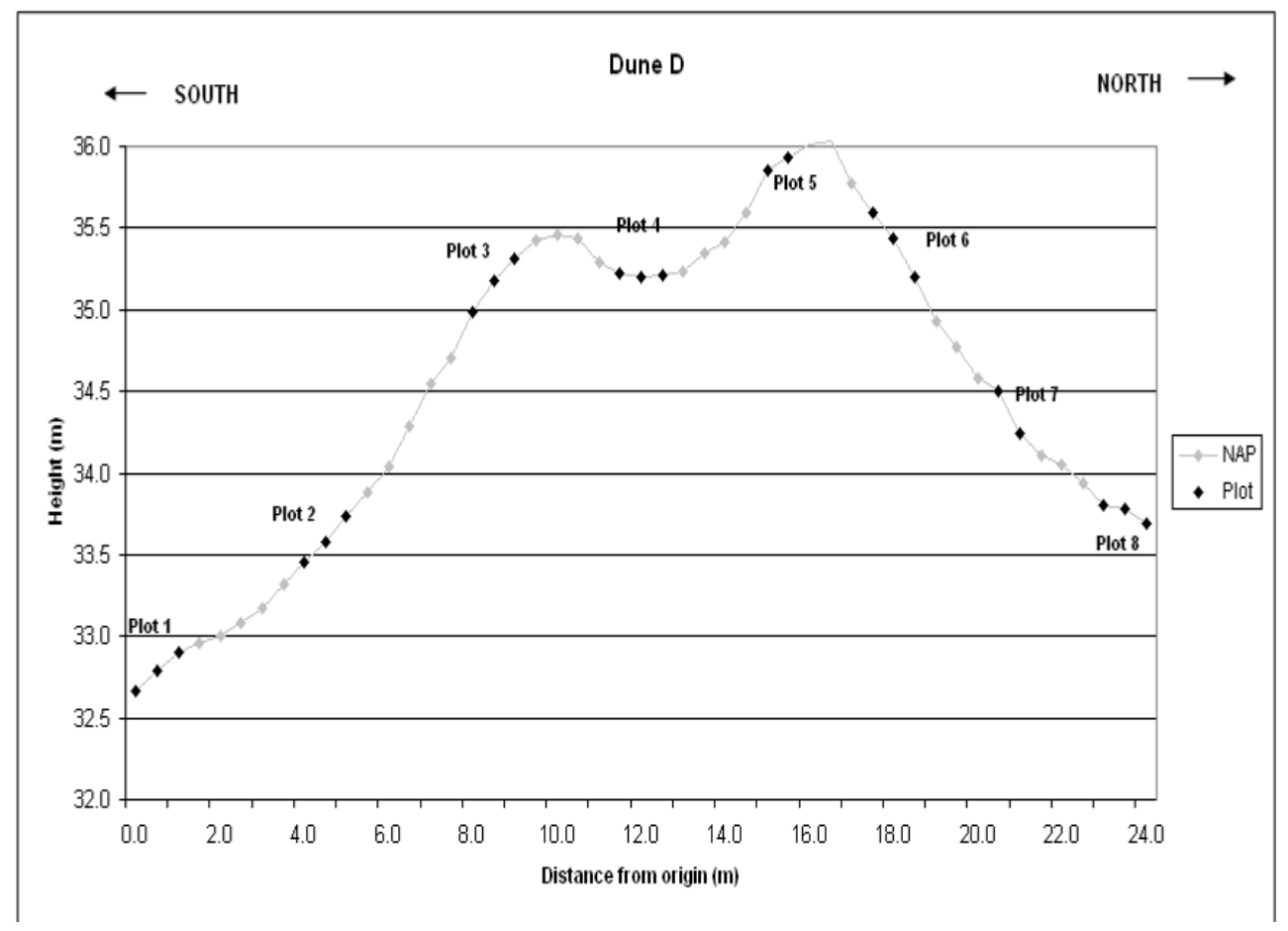

Figure 5: Experimental setup Dune D

For every plot the following field measurements were taken: location, slope and orientation, digital photograph, spectral measurements using Field Spec and also using Crop Scan.

Additionally, spectral-measurements of pure areas of the different targets were carried out using Crop Scan and Field Spec in order to analyze reflectance properties of the different targets. Additionally, a color aerial photograph of $25 \mathrm{~cm}$ pixel resolution was used to analyze its usability in measuring vegetation fractions. Once all the fieldwork measurements were carried out, different remote sensing methodologies were carried out to estimate the vegetation fractions of the samples.

The remote sensing techniques carried out were:

- Handheld Digital photograph classification

- Aerial photograph unmixing

○ Unmixing of spectral measurements (Field Spec and Crop scan)

\subsection{Remote sensing techniques}

\section{a). Digital photograph classification}

Field measurements: For every plot 3 digital photographs were taken. The viewing angle of the camera was set up perpendicular to the ground level at $0 \%$ slope. This resulted in photographs exactly on top of the plot, covering completely the $1 \mathrm{x} 1$ meters plot. 
Processing: The best photograph was selected for further analysis. All classification processes were made using ERDAS Imagine software. Two types of classification were carried out: supervised classification, where training areas are defined within the photo as a base for the classification process; and unsupervised classification where different targets are automatically separated based upon digital number $(\mathrm{DN})$ of pixels in the whole photo.

\section{Supervised classification}

- The first step was to analyze visually the number of classes (targets) present in the plot.

- Later, a 5x5 pixel low pass filter was applied to the image to eliminate local deviations, shadows for instance. However, the original image as well as the filtered images was further classified.

- Training areas for the different classes were performed (if present) and the DN-values per class were extracted from the image.

- Using the defined training areas, a classification was carried out using two parametric rules: maximum likelihood and minimum distance.

- Finally, the plot fractions were calculated by summing pixels of the different classes.

- Additionally, different combinations of training areas (DN-values) were tested in different plots in order to define a unique training area set for all the plots.

\section{Unsupervised classification}

- An unsupervised classification of the original image and of the image with a low pass filter (5x5) was performed. This approach considered a large number of classes (15) which were later re-grouped into the targets present in the image.

- Several combinations of classes were grouped in ArcGIS and displayed using different colors. This new groups were compared with the original photograph and training areas of the supervised classification to check its coherence.

\section{b). Aerial photograph unmixing}

Field measurements: An aerial photograph of the study area with 0.25 by 0.25 meter pixel resolution was bought. During the fieldwork campaign several ground control points were taken to check the spatial accuracy of the photograph. For this purpose, a Total station instrument was used.

Processing: After the photograph was checked (and corrected) linear unmixing technique was applied to estimate the fractions within the pixels. For this task the program IDL-ENVI was used.

The unmixing was done by using end-members, which are spectral signatures extracted from homogeneous areas where a pure target is present. In this case pure pixels of each target were identified in the aerial photograph and used as end members. For this purpose, information from the field campaign was used.

The end members were defined for the whole image and the complete aerial photograph was unmixed. Then for every plot the different fractions were extracted by clipping the unmixed image 
with a vector layer of the plots in ArcGIS. Finally the different fractions on each plot were calculated.

Additionally, a supervised classification was performed for the whole aerial photograph. For this purposes training areas were performed in the same areas where the end members were defined.

\section{c. $\quad$ Unmixing of spectral measurements (Field Spec and Crop Scan)}

Field measurements: Three Crop scan and Field spec measurements were taken for every plot. The average plot size for every measurement was $1 \mathrm{~m}^{2}$. The viewing angle for the crop scan instrument was 33 degrees and this was sufficient to cover the whole plot on the ground. With the Field spec three measurements were also taken per plot, and since there were covering about $90 \%$ of the plot the assumption made was that all the plots covered an area of $1 \mathrm{~m}^{2}$.

Processing: For the field measurements, all the plots were averaged based on the three recordings. Representative end members for each functional group were selected on the basis of their spectral signatures. ASCII files were created from the field measurement data of the plots and the selected end members.

A principal component analysis computation was performed on the ASCII files so as to carry out linear unmixing on the output. In order to use a linear mixture model there was a need to measure the spectral reflectance of the 'pure' end members. End member spectra were created by defining regions of interest (ROI) in the last three pixels of the PCA result representing the bare soil, vascular plants, and mosses respectively. Linear unmixing was then carried out. Since the first principal component band contains the largest percentage of data variance and the principal component second band contains the second largest data variance, and so on a subset of the bands (band 1-5 for Crop scan, band 1-8 for Field spec) was made as input for the unmixing process. A weight constraint of 1000 was given to the Crop scan and 10 for the Field spec to improve the unmixing result.

\section{Results and Discussions}

\subsection{Description of spectral signatures of different targets}

Analysis of spectral signature of different Earth Resource objects by remote sensing assists in identification. If the targets have differences in reflectance properties, then different techniques are used in order to identify and classify them.

Figure 6 shows the spectral signatures for the different targets of the dune ecosystem. Using Crop Scan and Field Spec, the spectral signature of mosses, grasses, lichens and bare soil are shown. The targets were selected by picking out a spectrum which was as representative as possible of that particular target in the field. The curve for the lichens and the bare soil are quite similar. This could be attributed to the fact that most of the lichens behave like dead vegetation and they also 
had some bare soil in them. The curve for the green moss and green grass are quite comparable though the reflectance of the grass is much higher. This is because the green grass has more green parts than the mosses; however, the chlorophyll absorption features in the visible part are almost the same.
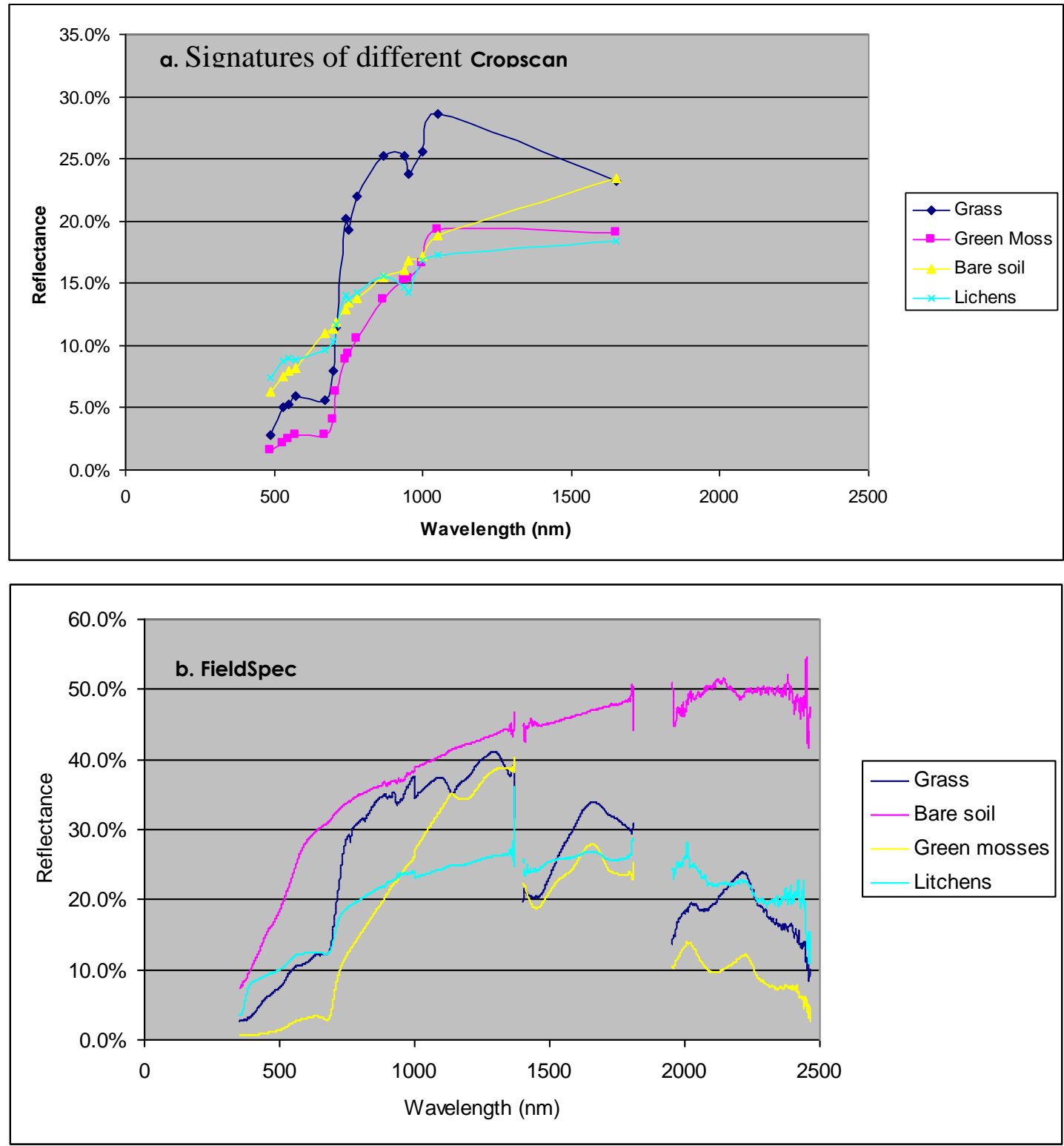

Figure 6 :Spectral targets in dune ecosystem 
Though the Field Spec is quite good at getting representative spectra of the different targets, it is heavily influenced by the prevailing weather conditions. When the Field Spec was used the weather, conditions were quite overcast and this resulted in a lot of calibration before the measurements were taken. However, in the end there was a lot of noise in the spectral signatures. The noise had to be removed in order to analyze the spectra clearly. The different targets look quite different spectrally with the Field spec than with the Crop scan though the behavior of the bare soil and the lichens follow the same pattern. There are some distinct differences in the visible part of the spectrum between the mosses and the grass; however, there are some parts where there are almost comparable.

Because grasses and mosses showed a great variation in water content and therefore in color, several measurements with Crop Scan were made during the field campaign. Figure 7 shows variation in reflectance when grasses go from wet to dry. Something similar occurs with mosses which vary from black (dry condition) passing by red and finally green (wet condition). When the grass becomes dry it looks similar to mosses.

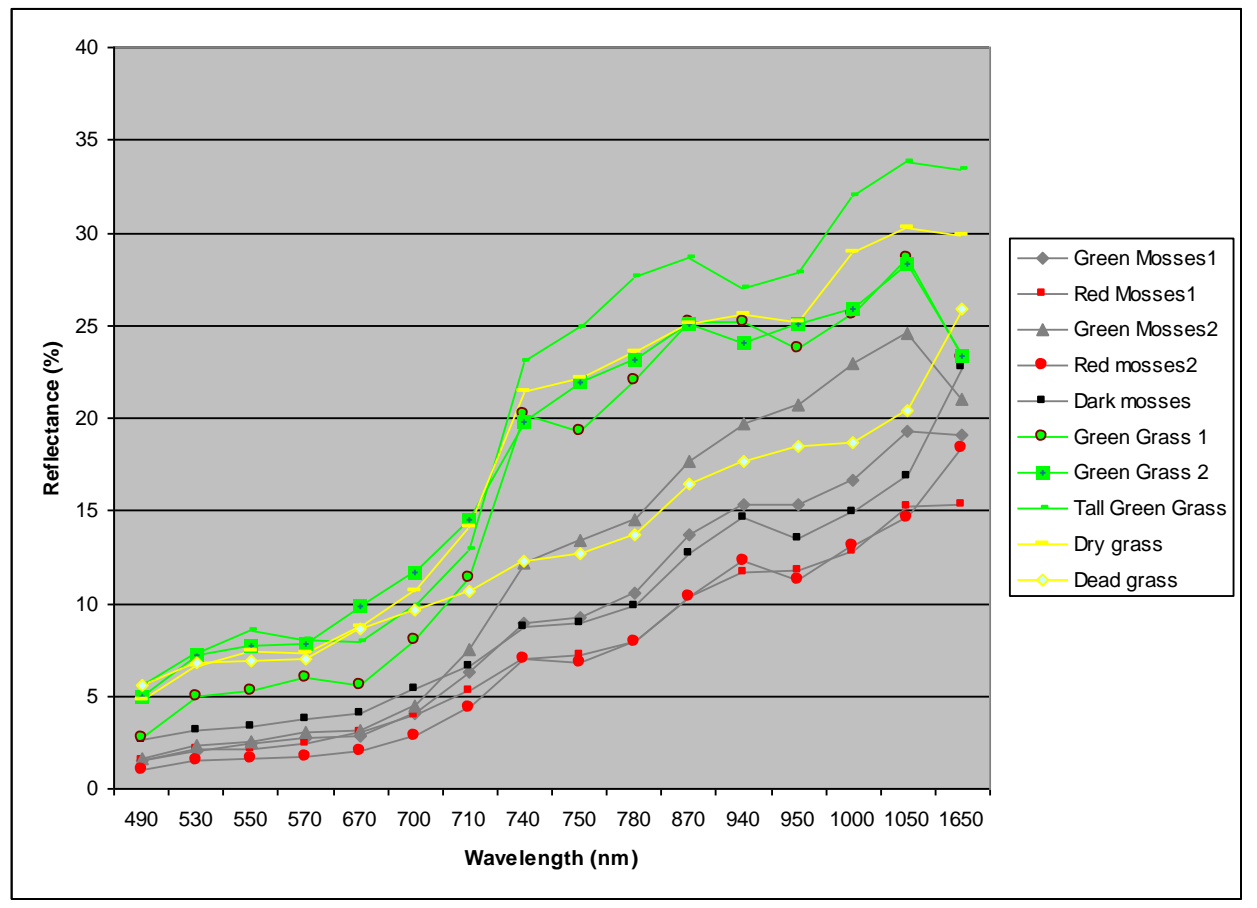

Figure 7:Spectral Signatures of different types of mosses and grass 


\subsection{Classification of Digital photographs}

\section{A. Preliminary analysis of Photographs}

To explore the possibilities of using a regular digital photo to estimate vegetation coverage, transect B plot 3 was taken as an example. This plot was selected since it is a mixture of mosses and bare soil, with some spots of lichens and vascular vegetation. These are all vegetation types, although the taller vascular plants are missing. The mosses are in some parts mixed with the bare soil. The digital photo of the plot was clipped around the plot corners that marked its edges. This results in a non-rectangular shape, as shown in Figure 8. This could be either due to a not perfectly squared plot, the slope percentage or a small error in the angle and location of the camera above the field. As a result, small errors will be made in the computation of the coverages. But those errors are expected to be small

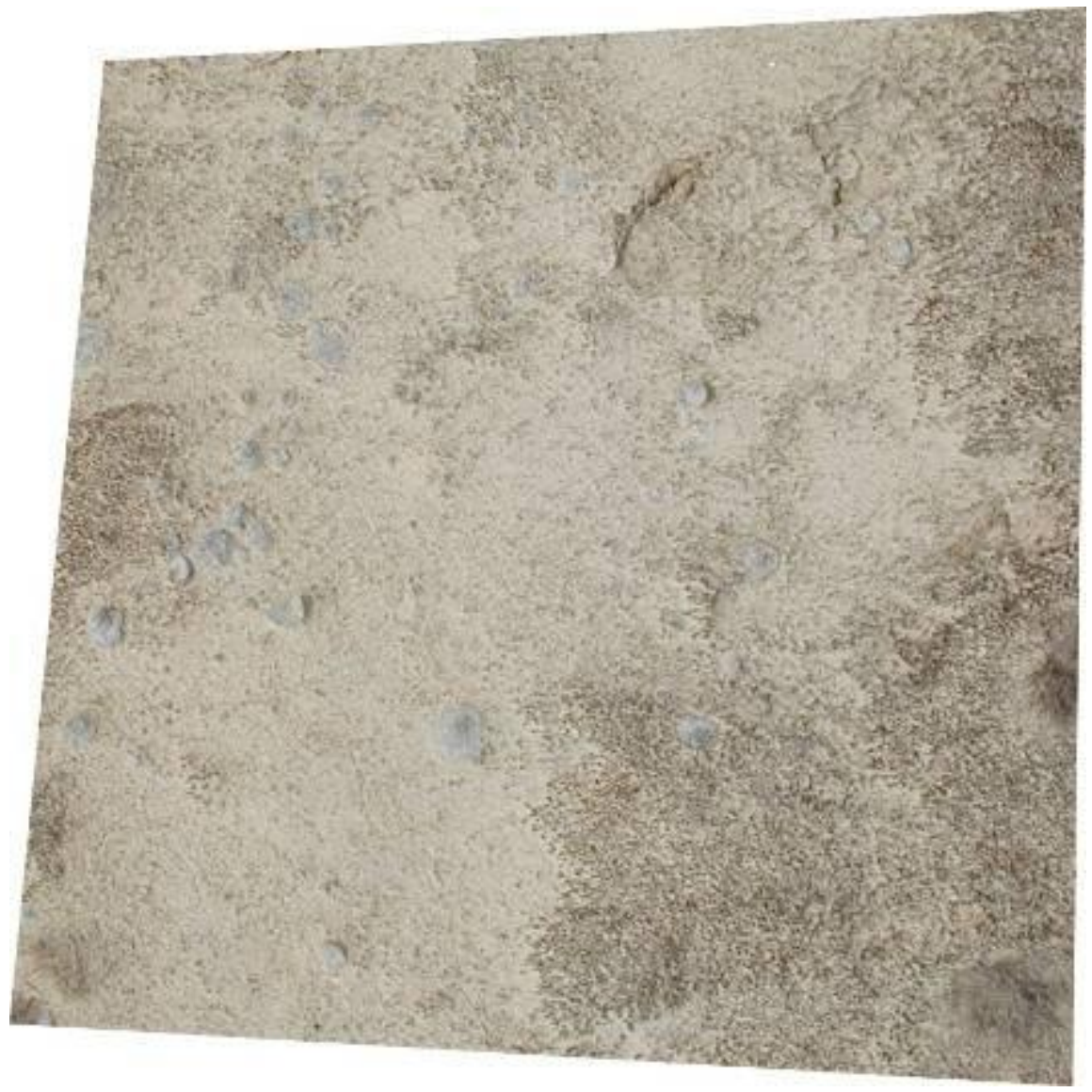

Figure 8: Digital image of plot B (1x1m)

\section{Supervised classification}

To classify an area from which the present vegetation types are known, a supervised classification was used. In this section Transect B is analyzed in detail, and in some points 
specifically plot B3 in which all the different types were represented. The vegetation types that were classified are mosses, lichens, vascular plants (mainly grasses) and bare soil.

The images of the digital camera are quite detailed compared to the normally used aerial photographs. Therefore, also a low pass filter of $5 \times 5$ is used to mix some of internal structure away. The results of this classification are shown in Figure 9.a-b-c-d.

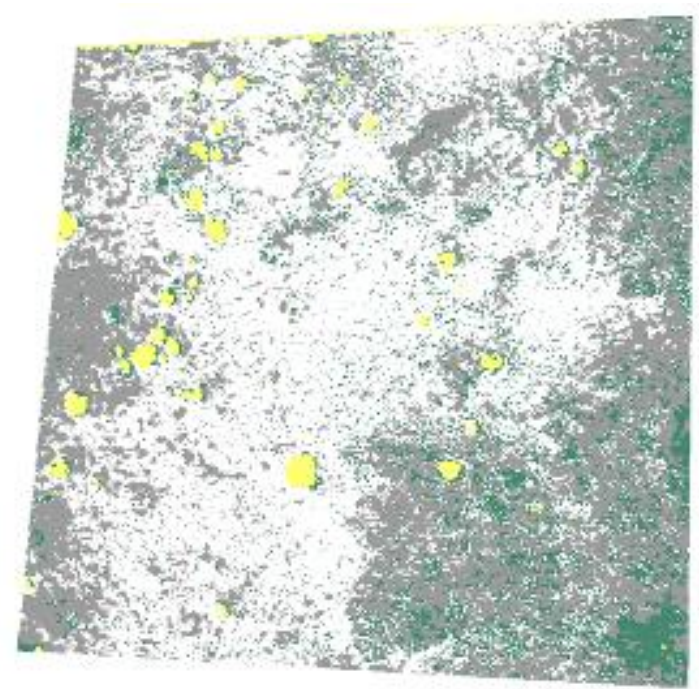

a. Maximum Likelihood

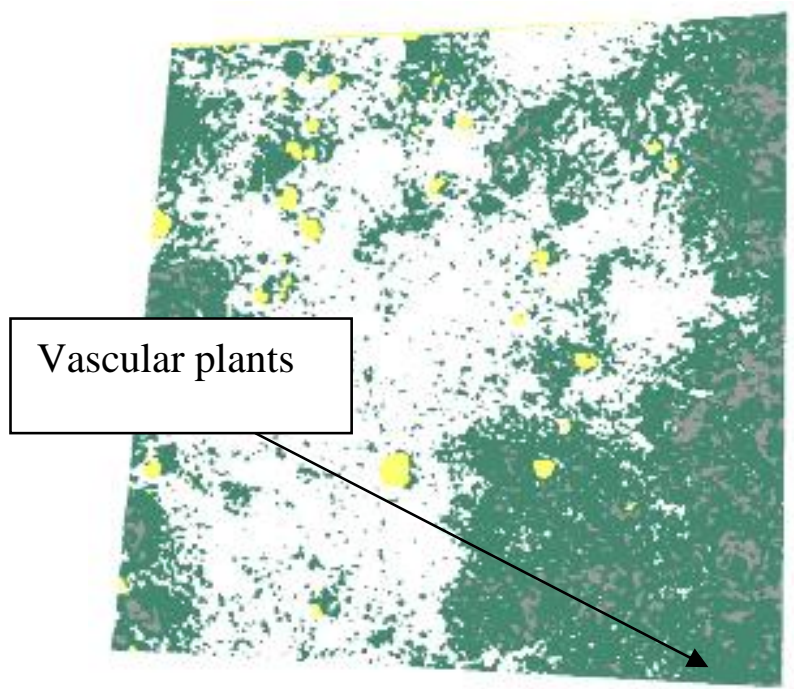

b. Low pass Maximum Likelihood

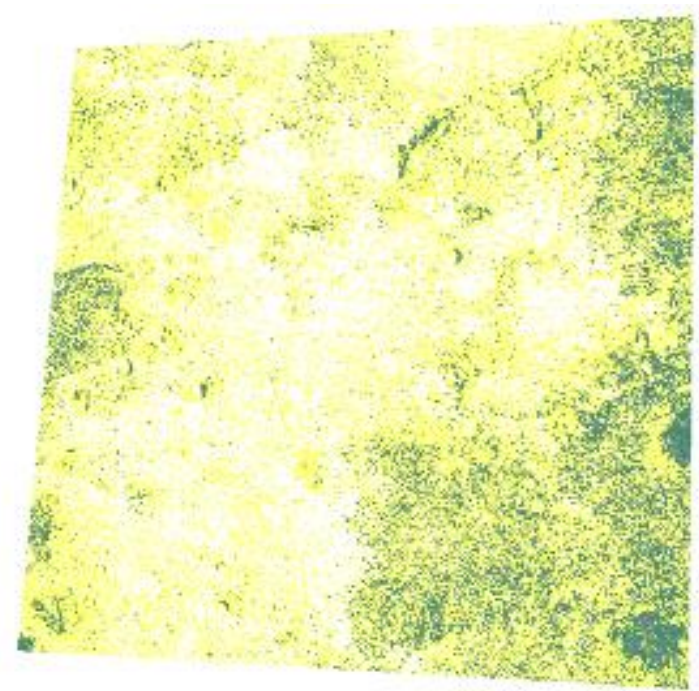

b. Minimum distance to means

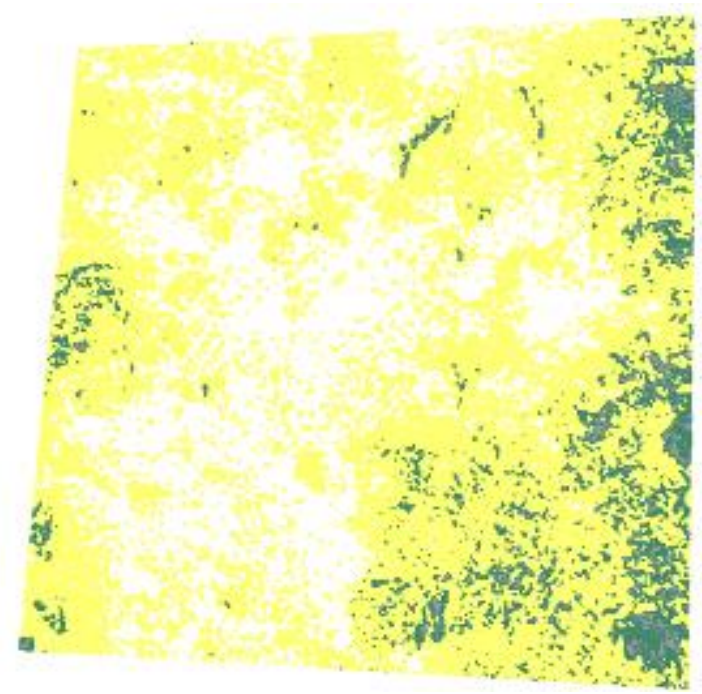

d. Low pass Minimum distance to means

Figure 9: Supervised classification results of plot B3

Legend

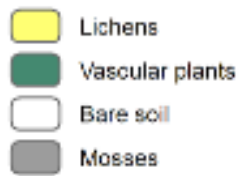


From these figures, it becomes clear that the different techniques are performing quite differently. While the maximum likelihood classification calculates a relative large amount of vascular plants and mosses, the minimal distance classification calculates a large percentage of lichens. This can be compared with the original photograph in Figure 8.

By comparing the classified images with original photograph, it becomes clear that the lichens are correctly identified by the maximum likelihood classification.

The minimal distance classifies the lichens incorrectly in plot B3 for both the original photograph and the photograph with the low pass filter. When the images classified with the minimal distance method were studied it became clear that the lichens are mixed with the mosses.

But also, another error occurred. In the lower right corner of Figure 9, two patches of vascular plants are visible. Those patches are in color very similar to the mosses by which they are surrounded. By this all techniques fail to separate the vascular plants from the other vegetation types without including part of the mosses. Root Mean Square values of different classification techniques (Table1)

Table 1:RMSE by the different classification techniques for transect B

\begin{tabular}{|c|c|c|c|c|c|c|c|}
\hline \multirow{2}{*}{$\begin{array}{l}\text { Supervised } \\
\text { classification } \\
\text { techniques }\end{array}$} & \multicolumn{6}{|c|}{ Plots in Transect B } & \multirow[b]{2}{*}{ Average } \\
\hline & B1 & B2 & B3 & B4 & B5 & B6 & \\
\hline $\begin{array}{l}\text { Maximum } \\
\text { Likelihood } \\
\text { (ML) }\end{array}$ & 0.16 & 0.17 & 0.02 & 0.07 & 0.04 & 0.02 & 0.08 \\
\hline $\begin{array}{l}\text { ML-Low Pass } \\
\text { filter }\end{array}$ & 0.20 & 0.20 & 0.13 & 0.07 & 0.03 & 0.00 & 0.10 \\
\hline $\begin{array}{l}\text { Minimum } \\
\text { distance (MD) }\end{array}$ & 0.15 & 0.14 & 0.15 & 0.05 & 0.11 & 0.03 & 0.11 \\
\hline $\begin{array}{l}\text { MD-Low Pass } \\
\text { filter }\end{array}$ & 0.20 & 0.17 & 0.17 & 0.07 & 0.06 & 0.00 & 0.11 \\
\hline
\end{tabular}

As already discussed for plot B3, Table1 shows that maximum likelihood performed better in the overall classification of the different plots.

When the fractions of all transects (A, B, C and D) were calculated using the best classification technique (Maximum Likelihood) and compared, the RMSE shown in Table 2 were found.

Table 2: RMSE for each plot along the transect

\begin{tabular}{|l|l|l|l|l|l|l|l|l|l|l|c|}
\hline Plot & $\mathbf{1}$ & $\mathbf{2}$ & $\mathbf{3}$ & $\mathbf{4}$ & $\mathbf{5}$ & $\mathbf{6}$ & $\mathbf{7}$ & $\mathbf{8}$ & $\mathbf{9}$ & $\mathbf{1 0}$ & Average \\
\hline A & 0.08 & 0.07 & 0.04 & 0.04 & 0.07 & 0.10 & 0.03 & 0.04 & 0.00 & 0.01 & 0.05 \\
\hline B & 0.16 & 0.17 & 0.02 & 0.07 & 0.04 & 0.02 & - & - & - & - & 0.08 \\
\hline C & 0.11 & 0.10 & 0.07 & 0.03 & 0.08 & 0.09 & 0.10 & 0.07 & - & - & 0.08 \\
\hline D & 0.06 & 0.13 & 0.10 & 0.06 & 0.14 & 0.02 & 0.02 & 0.01 & - & - & 0.07 \\
\hline
\end{tabular}


From Table2 it becomes clear that the different transects have an error of the same order of magnitude. The average error for all plots is 0.07 .

For plots with a relative high amount of vascular plants, a low pass filter could be used to improve the performance. This is most likely due to the internal structure that is present in those plants. By applying this filter some of this structure is mixed away, which results in a smaller color range, by which the classification resulted improved. When the low pass filter is applied at plots with a relative large amount of mosses and bare soils the accuracy decreases. This is due to the rapid changes in vegetation coverage, which is less distinctive when a low pass filter is used.

In those areas with a rapid succession of the mosses and bare soil the minimum distance performs slightly better. This is possibly due to the large average color difference between the mosses and the bare soil. But the errors are still quite large.

\section{Unsupervised classification}

To explore another classification technique to identify the different vegetation types in the plot, an unsupervised classification was conducted for 15 classes. All classes were given a different color. This analysis was carried out just for Plot B3. This is shown in Figure 10.

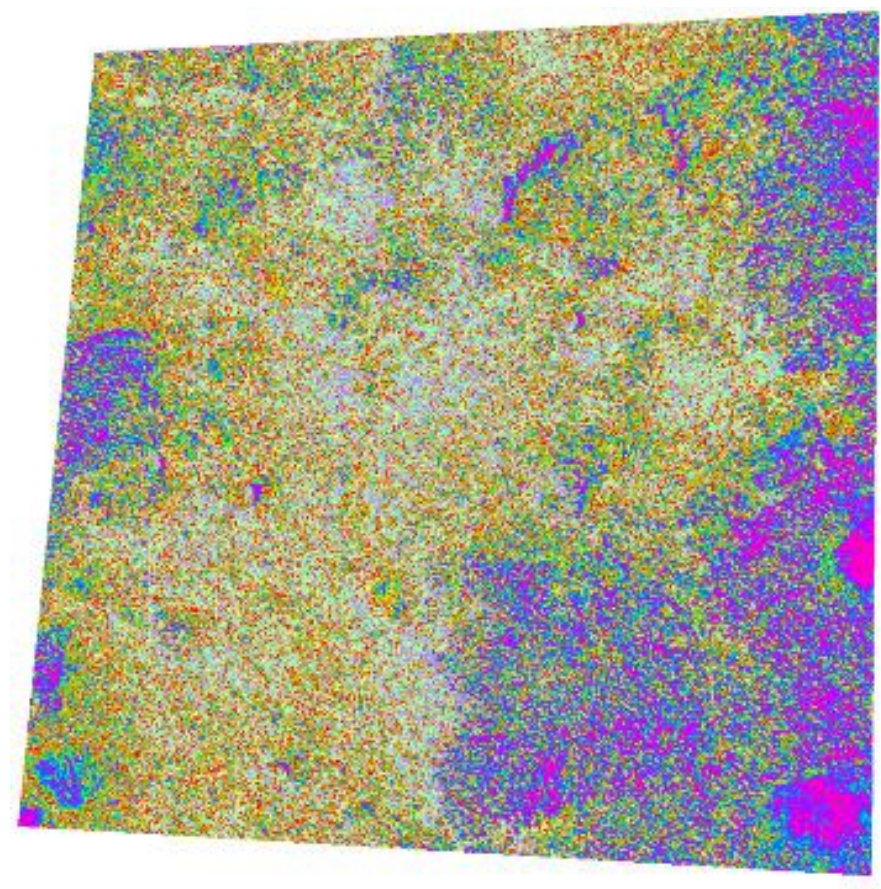

Figure 10: Classification of normal image using 15 unsupervised classes

Analyzing Figure 10,it becomes clear that the bare soil can be separated from the mosses and vascular plants. Especially in the central area of the plot yellow/white colors are visible, which corresponds to the abundance of bare soil in this area. Also, the patches of moss in the left part of the image were separated correctly. Problematic are the vascular plants and 
lichens. Due to their similar color, they are not distinguished in the unsupervised classification.

Furthermore, it is visible that the image is classified very patchy. Different colors are shown near to each other, which indicate changes in vegetation. From the normal photo, it is clear that most areas are relatively constant. Therefore, a low pass filter of $5 \times 5$ is used to filter those small differences out of the original photo. Afterwards the same unsupervised classification was used. The result of this is shown in Figure11.

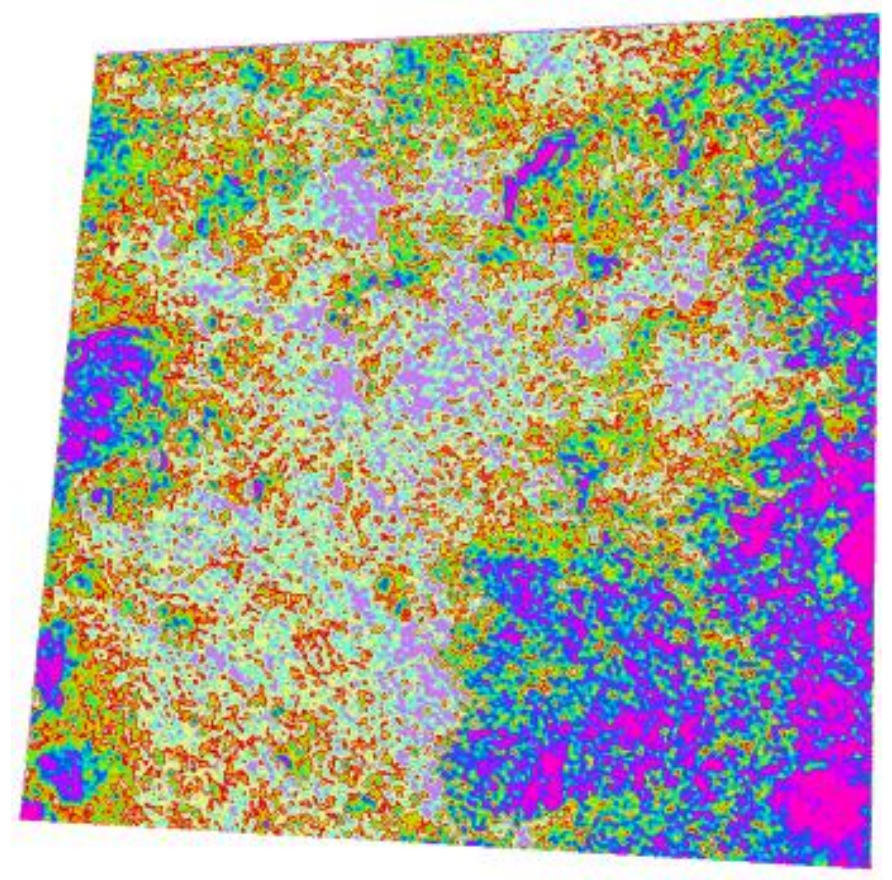

Figure 11: Classification of image with low pass generalization using 15 unsupervised classes

As expected the low pass filter generalized the results of the classification. But by visual interpretation no additional information is found. The lichens and vascular plants are still not separated from the mosses. Also, the differences between the mosses and bare soil did not become clearer.

\subsection{Unmixing of aerial photograph}

By unmixing the aerial photograph end members of the fractions of interest were taken by looking at the digital photographs. Due to the low number of bands, i.e. RGB, only three end members could be selected: vascular plant (grasses), mosses and bare soil. Therefore, unmixing process was very difficult to perform and results were meaningless, for many pixels negative fraction were obtained and often the fraction summed up more than 1 . Furthermore, RMSE using selected end members measurements as a ground truth were very high (Table 3). 
Table 3: Fractions of Transect B and RMSE calculated by Aerial photograph unmixing method

\begin{tabular}{|l|c|c|c|c|}
\hline Plot & Bare soil & Mosses & Vascular & RMSE \\
\hline B1 & 0.86 & 0.31 & 0.37 & 0.26 \\
\hline B2 & 2.83 & 0.00 & 0.00 & 0.88 \\
\hline B3 & 4.26 & 0.00 & 0.00 & 1.25 \\
\hline B4 & 1.11 & 0.04 & 0.00 & 0.49 \\
\hline B5 & 0.76 & 0.63 & 0.00 & 0.41 \\
\hline B6 & 1.57 & 0.00 & 0.25 & 0.57 \\
\hline
\end{tabular}

\subsection{Unmixing of spectral measurements (Field Spec and CropScan)}

To unmix the measurements of the Crop scan and the Field spec there was need to change the field measurements (Shimabukuro and Smith, 1991) into a so called "fake image" file where the unmixing process could be applied. The field measurements for the plots and the end members were converted into an image file by means of ASCII file where each plot corresponded to a 1 pixel of $1 \mathrm{x} 1$ meter. The image obtained was made of 1 row and 35 pixels (32 plots and the three end members). Figure 12a shows the image obtained for the Crop scan measurements. A similar image was obtained for the Field spec, but instead of having 16 bands, each pixel was confirmed by 1946 bands. This number (1946) was obtained after continual removal of noisy bands.

A principal component analysis was performed on the image shown in Figure $12 \mathrm{~b}$. The result was the image shown in Figure12 c-d-e. 


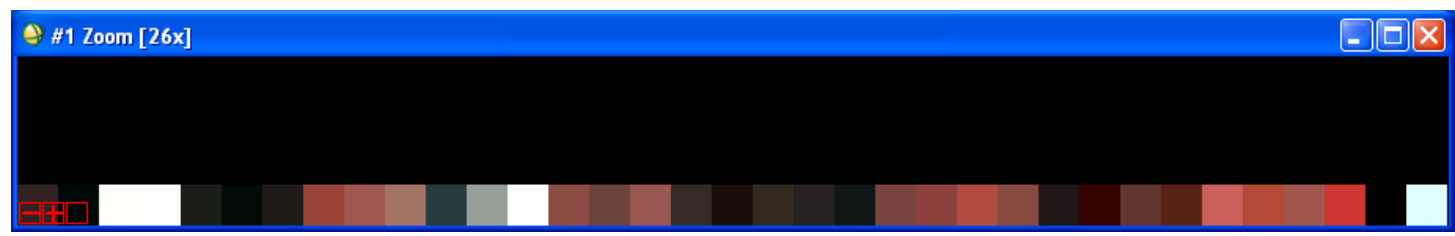

a. RGB image of the Crop scan dataset (each pixel corresponds to a plot of $1 \times 1$ meter pixel). The last 3 pixels correspond to the end members: from left to right vascular plants, mosses and bare soil.

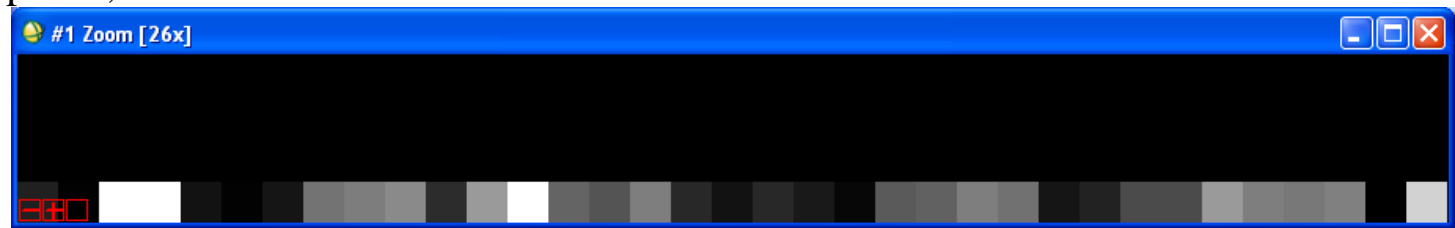

b. Grey scale of the first principal component output image. White colors indicate that most of the variation was grouped into the first principal component.

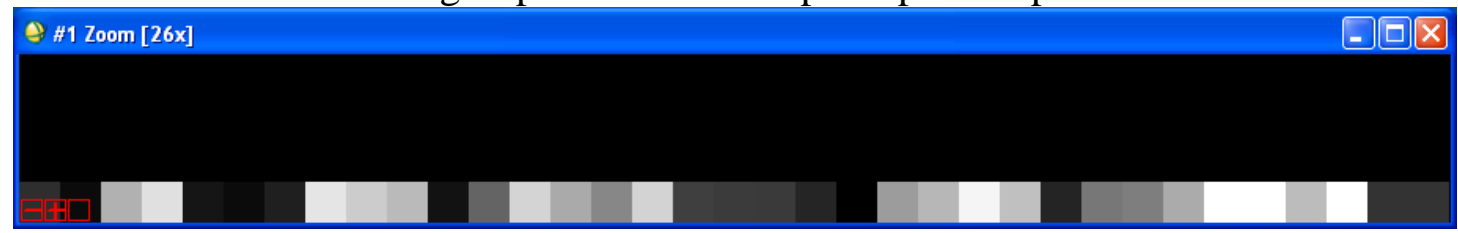

c. Unmixed fraction of vascular plants. White colors indicate high fractions while dark colors indicate low fractions.

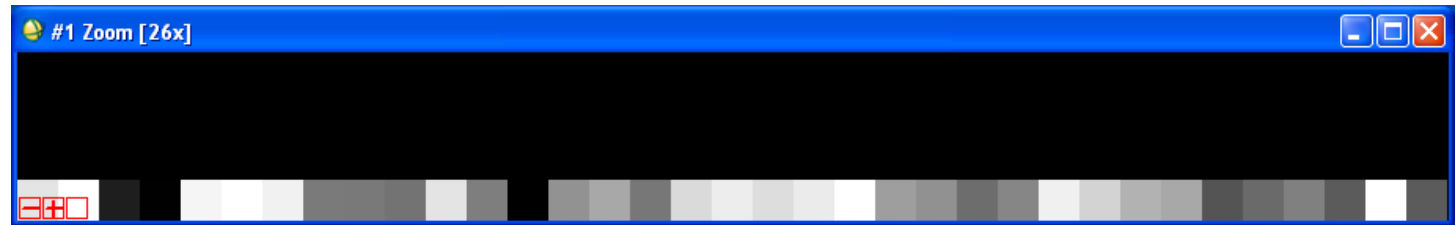

d. Unmixed fraction of mosses. White colors indicate high fractions while dark colors indicate low fractions.

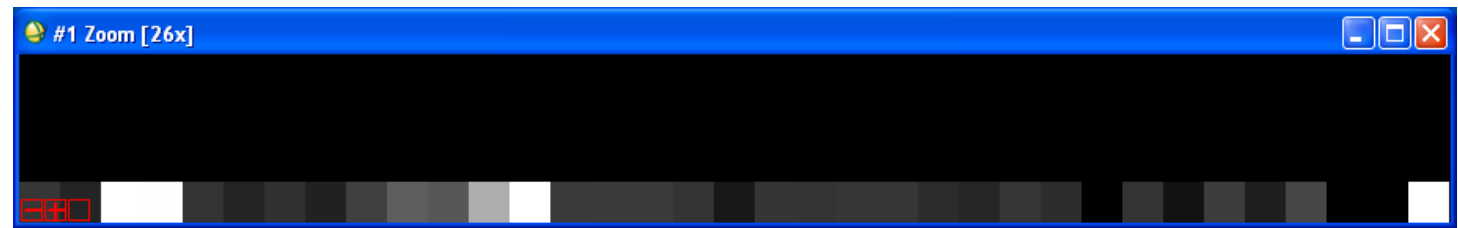

e. Unmixed fraction of bare soil. White colors indicate high fractions while dark colors indicate low fractions.

Figure 12: Fractions of transect A (plots 1-10), B (plots 11-17), C (plots 18-25) and D (plots 26-32) calculated by unmixing CROPSCAN spectral signature.

Linear unmixing was then carried out on the output of the principal component analysis. The results of the unmixing process for the Crop scan and Field spec plot 1 are represented in Figure 13 and 14 respectively. Plot 1 was specifically chosen because the results are quite interesting with negative fractions for some targets. Overall some of the plots have good fraction calculations with positive values for the targets; however, some also have negative fractions. 


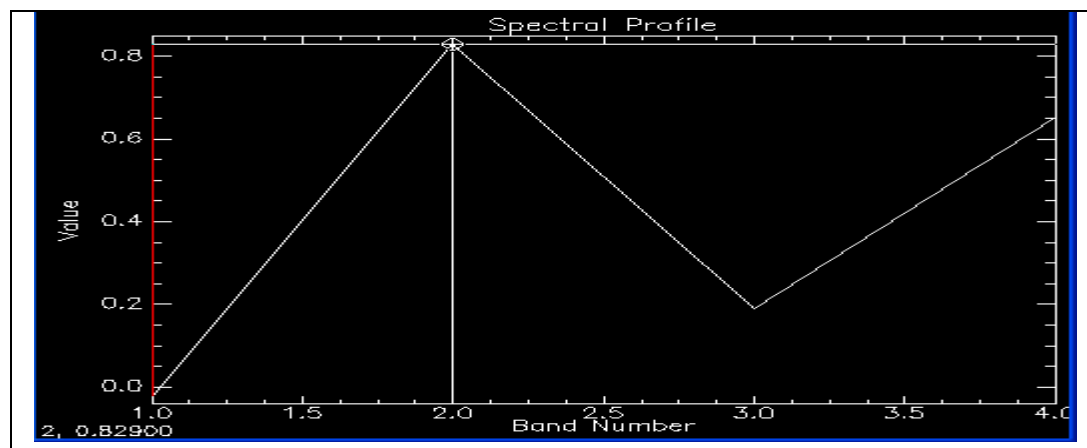

Mosses $=83 \%$

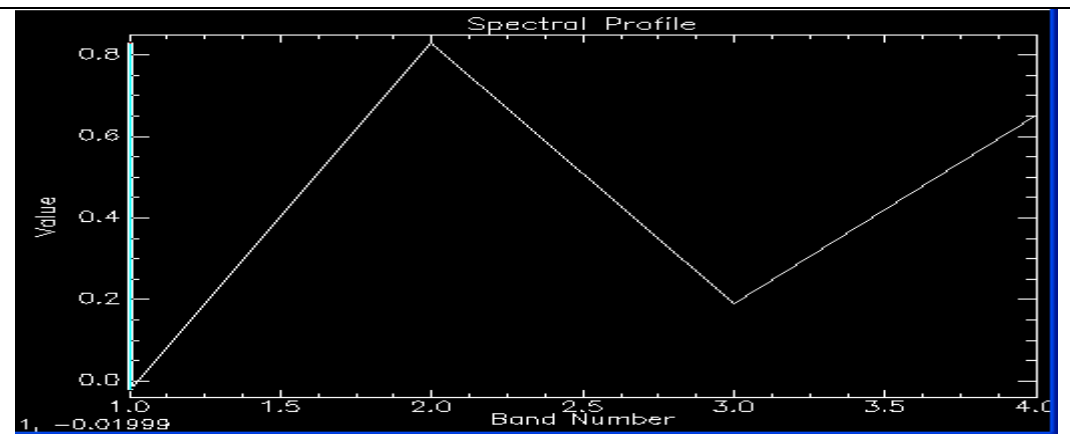

Vascular plants $=-1 \%$

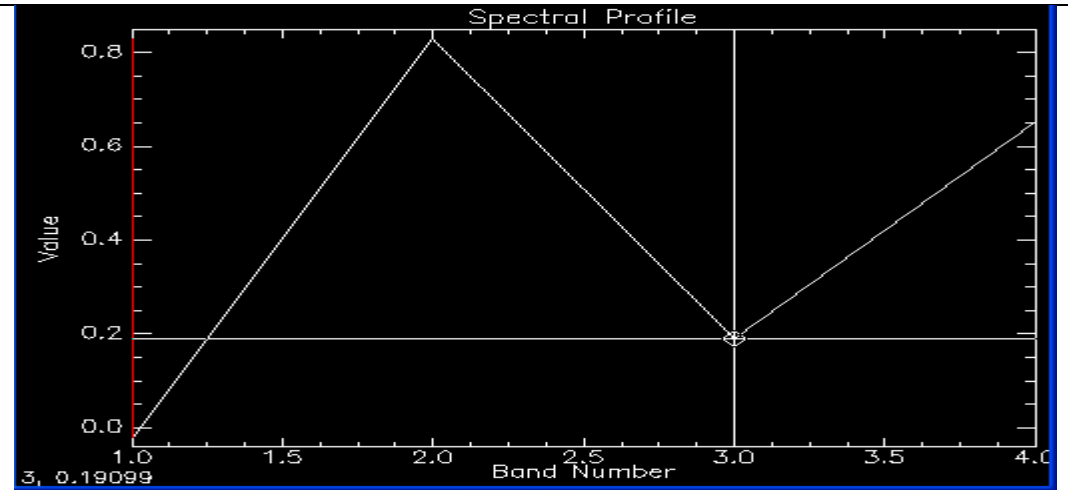

Bare soil $=19 \%$

Figure 13: Crop scan fractions of the three targets of Transect A Plot 1.

Bare soil fraction for this plot was $19 \%$ and mosses were $83 \%$. The result was negative for the vascular plants $(-1 \%)$. This was not expected even though the total of the three end members was adding to $100 \%$ so there was overestimation in some plots. The overestimation (meaning the sum of partial fraction is more than 1) was mainly occurring in vascular plants and mosses and spectrally these signatures were quite similar (Figure 13). However other 
plots gave all positive values as expected. The results presented in Figure 14 were obtained from the "Field spec fake image" for the same plot as for the "Crop scan image."

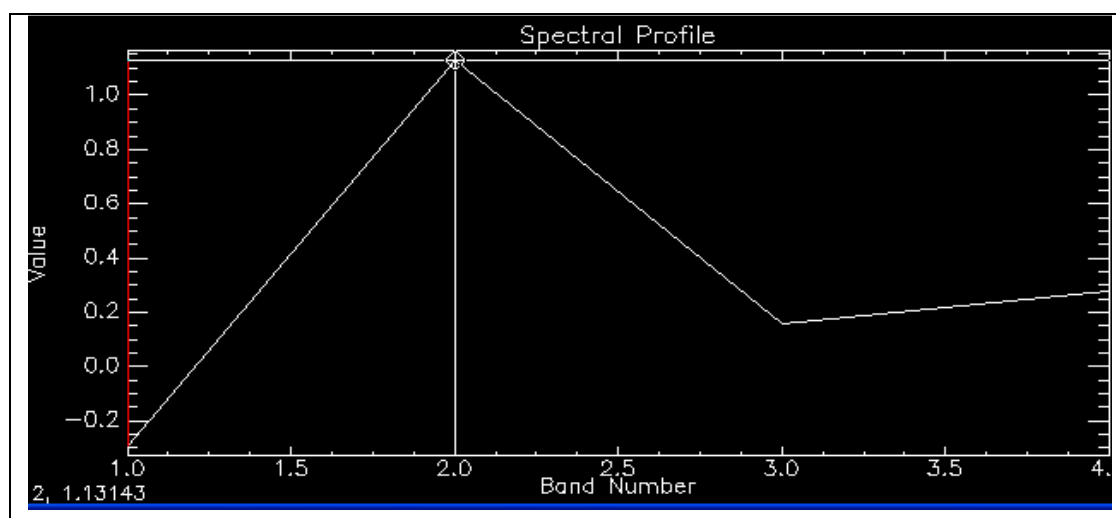

Mosses $=113 \%$

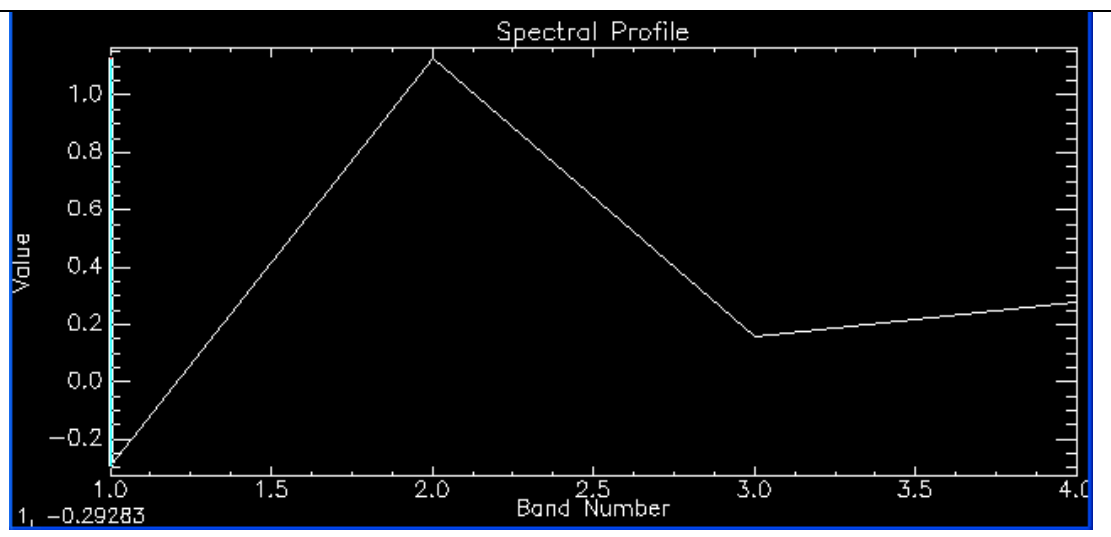

Vascular plants $=-29 \%$

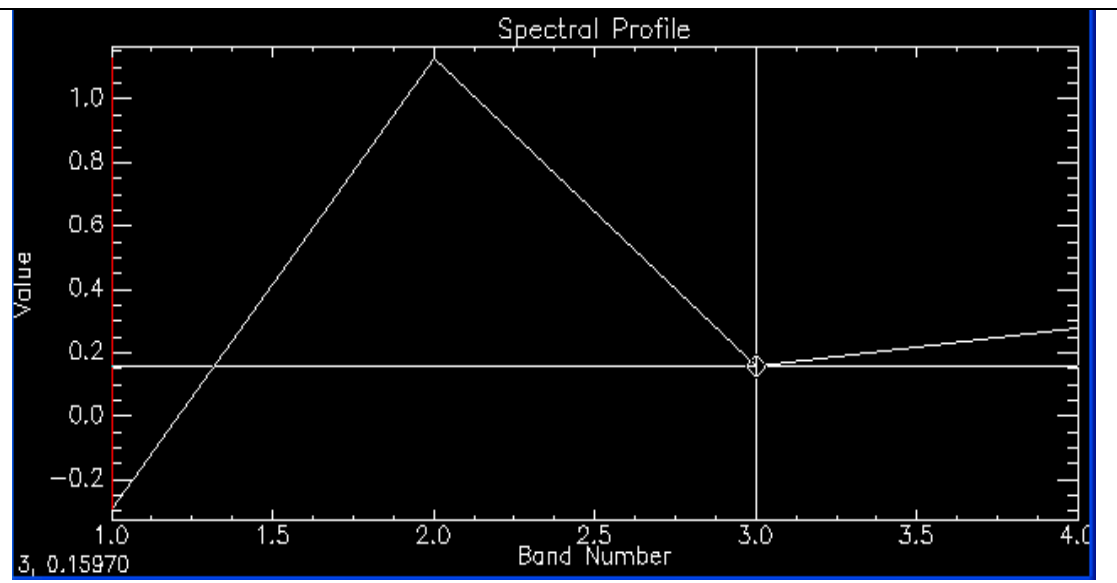

Bare soil $=16 \%$

Figure 14: Field spec fractions of the three targets of Transect A Plot 1 
The result for the Field spec are also overestimated for the same plot with mosses getting $113 \%$ of coverage and bare soil $16 \%$, however vascular plants have a negative value of -29 $\%$. The result for the Field spec and the Crop scan are quite similar, though there are some deviations in some plots. Table 4 shows results for transact B.

Table 4: Comparison of the Field spec and Crop scan fractions for transact B

\begin{tabular}{|c|c|c|c|c|c|c|c|}
\hline Method & Target & B1 & B2 & B3 & B4 & B5 & B6 \\
\hline \multirow{4}{*}{ Cropscan } & Vascular & 0.00 & 0.19 & 0.63 & 0.46 & 0.33 & 0.63 \\
\cline { 2 - 8 } & Mosses & 0.83 & 0.21 & 0.00 & 0.33 & 0.47 & 0.17 \\
\cline { 2 - 8 } & Bare soil & 0.30 & 0.60 & 1.04 & 0.20 & 0.21 & 0.21 \\
\cline { 2 - 8 } & RMSE & 0.14 & 0.17 & 0.33 & 0.20 & 0.19 & 0.18 \\
\hline \multirow{5}{*}{ Fieldspec } & Vascular & 0.00 & 0.00 & 0.34 & 0.36 & 0.43 & 0.41 \\
\cline { 2 - 9 } & Mosses & 0.90 & 0.38 & 0.00 & 0.54 & 0.35 & 0.45 \\
\cline { 2 - 8 } & Bare soil & 0.35 & 0.73 & 1.16 & 0.10 & 0.22 & 0.14 \\
\cline { 2 - 8 } & RMSE & 0.16 & 0.18 & 0.31 & 0.21 & 0.17 & 0.18 \\
\hline
\end{tabular}

There is overestimation of the fractions in both the Crop scan and Field spec for plot B1 and B3 respectively and B4 for the Field spec. PlotB6 showed good fraction estimations for both the Field spec and the Crop scan. The results are almost similar for some targets, for example bare soil in the plot B5, there were some big deviations for the mosses and the bare soil. These deviations can be attributed to variation in weather condition during the measurement day and frequent field spec calibrations. It was only the bare soil coverage's across areas of the sample plots and around the plots that was completely homogenous; the different recording areas would have no effect. As the bare soil coverages are very heterogeneous, the mentioned effect could have a negative influence for the accuracy of the spectral unmixing results when compared to the Photographic results.

With reference to the spectral signatures obtained for the various end members there was a huge similarity between the end members for vascular plants and mosses. This could also have led to the overestimation because spectrally it was difficult to distinguish between these two targets. There was also a lot of variation within the measurements for certain ends members and finding a representative signature for all the variation was quite challenging, for example there was dry grass, green grass and dead grass. In the end, only one spectra were chosen to represent all this variation in grass and this may have led to errors in the estimation. This could be because grass is quite easy to distinguish spectrally from the other two targets. The other reason why the results were not as accurate as expected may be due to the fact that the end members chosen may have been different from the variation in the plots.

One may expect that the unmixing results should become better if more end members are chosen. For example, to use green moss, dark moss, dead moss, dry moss, red moss and 
different species of Lichens as different end members. However, after performing a Principal Component Analysis it becomes clear that only in about 5 to 10 bands variation is present. This practically means that of the 16 bands in the Crop scan instrument and the 1946 used bands in the Field spec instrument, only 5 to 10 bands can be of value to the unmixing process. Therefore, only 5 to 10 minus 1 end members can be selected.

Finally, we could not choose a day with optimal weather condition in the days prior to the measurements due to the limited time frame. As the reflectance of the different classes is highly dependent on the state of the vegetation and its water content, it would have been better if we were able to acquire the data on a free-cloud day

\section{Conclusions and Recommendations}

\subsection{Conclusions \\ Hand held camera image}

Chance of having large errors by classifying the digital photograph is high. This can either be due to a misclassification of a training area, or due to the close resemblance between classes. The reduced spectral resolution of this kind of images ( 3 bands in the visual part of the spectrum) constitutes a limitation for the classification process.

The Maximal likelihood classification method (ML) has the best overall performance. It performs especially well in comparison to the other techniques to separate bare soil from mosses.

For areas with only mosses and vascular plants, a low pass filter improves the classification results. This is probably due to the structure and internal shadowing in these plants, which is reduced by the low pass filter.

With the current data, it is not possible to generate a table of DN-values which could be used to classify all of the plots. Differences in vegetation are too big. Also, differences in illumination and the behavior of the camera resulted in different colors and brightness. Unsupervised classification is not able to identify all the present classes. Lichens are difficult to separate from the bare soil and vascular plants from the mosses.

\section{Aerial photograph}

Unmixing of the aerial photograph did not yield useful results. RMSE ranged between 0.4 and 2.2 due to the limited number of bands (3). This theoretically resulted in only 3 end members, which is to limited for this purpose. Therefore, this method is currently not suitable for hydrologic purposes. 
Classification of the aerial photograph yielded better results, especially on a larger scale, for instance, for a complete aerial photograph. Results on a plot level yield better results than unmixing, but have a very coarse resolution and did not identify lichens.

\section{Field spec \& Crop scan}

The success of Crop scan and Field spec is low since only some plots gave good results but in most plots the fraction exceeded and/or contained negative values.

The average RMSE of the transects ranged between 0.14 and 0.20 which is comparable with the aerial photograph and unmixing result.

Definition of good end members to carry out unmixing was very difficult since the targets showed a large spectral variation according to the field measurements.

\section{General conclusion}

According to this study and the data acquired during this research, hand held camera method is almost as accurate as aerial camera but was more time consuming. Therefore, from the remote sensing methods, this is the best method.

\subsection{Recommendations}

In the spectral unmixing analysis of this study, Field spec recordings were used as end members to unmix Field spec plot data and Crop scan recordings were used as end members for unmixing Crop scan plot data. In addition, one may want to explore the possibility to cross-combine the two instruments. Using Crop scan end members for unmixing Field spec data will not be viable because of the limited number of bands in the Crop scan instrument compared to the Field spec measurement (i.e. 16 vs. 2500). Using Field spec end members to unmix Crop scan data, however, may be useful. If one would decide to do so, the Field spec end members should be resampled to the number of bands and the band widths of the Crop scan instrument, which requires an extra step in the unmixing process. Because of the limited time in this study, it was not included here. The plot size could also be increased in the future to eliminate the problem of the small plot size as used in this research.

Considering that spectral signatures of mosses and vascular plant showed great variation and some overlapping between them, it would be interesting to analyze if differences can be found in the red edge. This can be done by applying continuum removal in the spectral region between $550 \mathrm{~nm}$ and $750 \mathrm{~nm}$ and by studying the chlorophyll absorption depth. If differences were found, then vegetation index would be calculated in order to identify and quantify fractions of these two targets. 
Furthermore, regarding the Field spec measurements it is recommended to choose measurement days when cloud conditions are more stable. Unfortunately, this was not possible during this study as a result of the limited timeframe.

In order to improve the hand-held digital camera method, it is recommended to take into account the following technical aspects. During field measurements, to use a fixed shutter time and illumination for the camera in order to make comparison between images more reliable. In order to correct for changing solar illumination or cloud conditions a reference reflectance panel can be photographed outside the plot. Thirdly, an infrared band could be added to the camera in order to capture more spectral information and to make the results more useful and reliable. Fourthly, a correction method could be defined in case the camera was not positioned orthogonally to the field, thereby creating non-square plots in the photographs.

For improving the aerial photography method, it is important to use the most recent imagery and to only compare aerial imagery with other field data if the period of recording is more or less equal. This in relation to seasonality and yearly change in vegetation patterns.

\section{REFERENCES}

Alongi, D.M., (2008): Mangrove forests: resilience, protection from tsunamis, and responses to global climate change. Estuarine, Coastal and Shelf Science, 76, pp. 113.

Bartholy, J. And Pongracz, R., (2005): Extremes of ground based and satellite measurements in the vegetation period for the Carpathian Basin. Physics and Chemistry of the Earth, 30, pp. 81-89.

Chauhan, H.B. And Dwivedi, R.M., (2008): Inter Sensor Comparison Between Resourcesat Liss Iii, Liss Iv And AWIFS with reference to coastal landuse/landcover studies. International Journal of Applied Earth Observation and Geoinformation, 10,pp. $181-185$.

Crop scan inc. (2002) Homepage (http://www.cropscan.com/thecomp.html, May $\left.4^{\text {th }} 2016\right)$

Dahdouh-Guebas, F., Verheyden, A., De Genst, W., Hettiarachchi, S. And Koedam, N.( 2000): Four decade vegetation dynamics in Sri Lankan mangroves as detected from sequential aerial photography: a case study in Galle. Bulletin of Marine Science, 67, pp. 741-759. 
Dahdouh-Guebas, F., Van Hiel, E., Chan, J.C.-W., Jayatissa, L.P. And Koedam, N., (2005): Qualitative distinction of congeneric and introgressive mangrove species in mixed patchy forest assemblages using high spatial resolution remotely sensed imagery (IKONOS). Systematics and Biodiversity, 2, pp. 113-119

FAO, (2007): Mangrove Guidebookfor Southeast Asia (RAP/2006/07) (Bangkok, Thailand: Dharmasarn Co., Ltd).

Fromard, F., Vega, C. And Proisy, C., (2004): Half a century of dynamic coastal change affecting mangrove shorelines of French Guiana. A case study based on remote sensing data analyses and field surveys. Marine Geology, 208, pp. 265-280.

Frihy, O. E.: (2001): 'The necessity of environmental impact assessment (EIA) in implementing coastal projects: Lessons learned from the Egyptian Mediterranean coast', Ocean Coastal Manage. 44,489-516.

Gilman, E., Ellison, J., Duke, N.C. And Field, C., (2008): Threats to mangroves from climate change and adaptation options: a review. Aquatic Botany, 89, pp. 237-250.

Giri, C., Pengra, B., Zhu, Z., Singh, A. And Tieszen, L.-L., (2007): Monitoring mangrove forest dynamics of the Sundarbans in Bangladesh and India using multi-temporal satellite data from 1973 to 2000. Estuarine, Coastal and Shelf Science, 73, pp. 91100.

Lucas, R.M., Ellison, J.C., Mitchell, A., Donnelly, B., Finlayson, M. And Milne, A.K., (2002): Use of stereo aerial photography for quantifying changes in the extent and height of mangroves in tropical Australia. Wetlands Ecology and Management, 10, pp. $161-175$

McGwire, K., T. Minor, F. Fenstermaker (2000): Hyper-spectral mixture modeling for quantifying sparse vegetation cover in arid environments. Remote Sensing of Environment 72(3): 360- 374.

Meer, F.D., van de, S.M. de Jong (2001): Imaging Spectrometry-Basic Principles and Prospective Applications. Kuwer Academic Publishers, Dordrecht/Boston/London.

Mumby, P.J., Green, E.P., Edwards, A.J. And Clark, C.D., (1999): The cost-effectiveness of remote sensing for tropical coastal resources assessment and management. Journal of Environmental Management, 55, pp. 157-166.1648 B 
Reyniers, M., E. Vrindts, J. de Baerdemaeker (2006): Comparison of an aerial-based system and an on the ground continuous measuring device to predict yield of winter wheat. European Journal of Agronomy 24: 87-94

Satyanarayana, B., (2007): Application of Remote Sensing: An Approach for Distinguishing Vegetation Structure and Decadal Changes in Mangroves (Kuala Terengganu, Malaysia: University Malaysia Terengganu).

Shimabukuro, Y.E. and J.A. Smith (1991): The least-squares mixing models to generate fraction images derived from remote sensing multispectral data. I.E.E.E. Transactions on Geoscience and Remote Sensing 29(1), 16-20

Simard, M., Rivera-Monroy, V.H., Mancera-Pineda, J.E., Castan ${ }^{2}$ Eda-Moya, E. And Twilley, R.R., (2008): A systematic method for 3D mapping of mangrove forests based on Shuttle Radar Topography Mission elevation data, ICEsat/GLAS waveforms and field data: application to Ciénaga Grande de Santa Marta, Colombia. Remote Sensing of Environment, 112, pp. 2131-2144.

Til, T. van, A. Bijlmer, R. de Lange (2004): Seasonal variability in spectral reflectance of coastal dune vegetation. European Association of Remote Sensing Laboratories eProceedings 3

Unep-Wcmc, (2006): In the Front Line: Shoreline Protection and other Ecosystem Services from Mangroves and Coral Reefs (Cambridge, UK: UNEP-WCMC).

Walters, B.B., Ro“" Nnba“ Ck, P., Kovacs, J., Crona, B., Hussain, S., Badola, R., Primavera, J.H., Barbier, E.B. And Dahdouh Guebas, F., (2008): Ethnobiology, socioeconomics and adaptive management of mangroves: a review. Aquatic Botany, 89, pp. 220-236

Wikipedia, the free encyclopedia (2010): Imaging Spectroscopy, April 23rd 2010 (http://en.wikipedia.org/wiki/Imaging_spectroscopy, June 4th 2016)

Zhang, Y., Wang, W., Wu, Q., Fang, B. And Lin, P., (2006): The growth of Kandelia candel seedlings in mangrove habitats of the Zhangjiang estuary in Fujian, China. Acta Ecologica Sinica, 26, pp. 1648-1656 